\title{
KẾT QUẢ ĐIỀU TR! LÕM NGỰC BẨM SINH BẦNG PHƯƠNG PHÁP NUSS CẢI TIẾN TẠI BỆNH VIỆN HŨ̉U NGHỊ VIỆT ĐỨC
}

Vũ Văn Bộ ${ }^{*}$, Phạm Hũu Lu**

\section{TÓM TẮT}

197 bệnh nhân được phẫu thuật bằng phương pháp Nuss cải tiến sử dụng đường vào nội soi và luồn thanh dẫn từ bên trái có: Tuổi trung bình

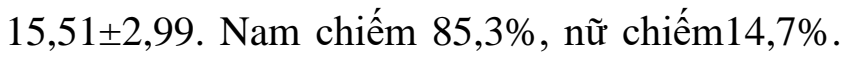

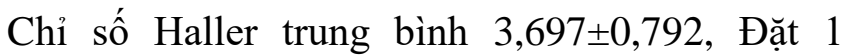
thanh chiếm 98,5\%, 2 thanh chiếm 1,5\%. Thời gian mổ trung bình $45,48 \pm 13,2$ phút. Thời gian nằm viện sau mổ trung bình $5,32 \pm 2,38$ ngày. Còn tồn dư khí sau mổ: 02 trường hợp. Biến chứng sau mổ: 01 trường hợp. Không có trường hợp nào chảy máu trong và sau mổ, không có tử vong. Phẫu thuật Nuss cải tiến có nội soi hỗ trợ với đường tiếp cận vào lồng ngực từ bên trái điều trị bệnh lõm ngực bẩm sinh là phương pháp hiệu quả, an toàn và ít biến chứng.

Tù khóa: Lõm ngực bẩm sinh, phương pháp Nuss trái qua phải, Việt Đức.

\section{RESULTS OF TREATING PECTUS EXCAVATUM BY THE MODIFY NUSS PROCEDURE AT VIET DUC UNIVERSITY HOSPITAL}

\section{SUMMARY}

197 patients underwent the modify Nuss procedure using endoscopic access and a lefthand guide to the left: Average age $15.51 \pm 2.99$. Male accounted for $85.3 \%$, female accounted for 14.7\%. Average Haller index 3,697 \pm 0,792, placing 1 bar accounting for 98.5\%, 2 bars accounting for $1.5 \%$. The average surgery time is $45.48 \pm 13.2$ minutes. The average length of hospital stay after surgery is $5.32 \pm 2.38$ days.
Residual air remains after surgery: 02 cases. Postoperative complications: 01 case. There were no cases of bleeding during and after surgery, no deaths. Modify Nuss procedure with approarching port from the left side of the chest cavity for treating pectus excavatum is an effective, safe and less complicated method.

Keywords: Pectus Excavatum, left-right Nuss method, Viet Duc.

\section{I. ĐẶT VẤN ĐỀ}

Phẫu thuật điều trị lõm ngực bẩm sinh (LNBS) được Donal Nuss đề xuất năm 1998 sau 10 năm kinh nghiệm[1], đã được ứng dụng rộng rãi trên thế giới kết hợp với nội soi lồng ngực hộ trợ chủ yếu từ phải qua trái[2]. Tuy nhiên các nghiên cứu cũng đưa ra các biến chứng có thể sảy ra liên quan tới phẫu thuật như: Tràn khí màng phổi, tổn thương phổi, tổn thương tim, cơ hoành, trocar chọc vào gan phải, nhiễm trùng, dị ứng thanh đỡ, di lệch thanh...[3-4]. Ở Việt Nam phẫu thuật Nuss bắt đầu được thực hiện năm 2007 tại bệnh viện Chợ Rẫy dưới sự hỗ trợ từ phẫu thuật viên Hàn Quốc [5]. Tại bệnh viện hữu nghị Việt Đức, phẫu thuật Nuss có nội soi hỗ trợ bắt đầu được triển khai từ năm 2010[6] với đường tiếp cận khoang lồng ngực từ phải qua trái hoặc từ trái qua phải. Đến nay phẫu thuật theo phương Nuss cải tiến (sử dụng nội soi hỗ trợ và đườn tiếp cận khoang lồng ngực từ trái qua

* BV Đa khoa Vĩnh Phúc

** BV HN Việt Đức, Truoòng ĐH Y Hà Nội

Ngườ chịu trách nhiệm khoa học: TS. Phạm Hũu Lu

Ngày nhận bài: 01/07/2019 - Ngày Cho Phép Đăng: 20/07/2019

Phản Biện Khoa họ: PGS.TS. Đặng Ngọc Hùng GS.TS. Lê Ngoc Thành 
phải) đã đi vào thường quy. Mục tiêu của nghiên cưu là nhận xét kết quả của phẫu thuật Nuss cải tiến điều trị bệnh lõm ngực bẩm sinh tại bệnh viện hũu nghi Việt Đức.

\section{II. ĐỐI TƯợNG VÀ PHƯƠNG PHÁP} NGHIÊN CÚ'U

Bao gồm những bệnh nhân lõm ngực bẩm sinh được phẫu thuật bằng phương pháp Nuss cải tiến trong thời gian từ 2016 đến 2018 (03 năm). Phương pháp nghiên cứu: Mô tả cắt ngang hồi cứu. Các biến số nghiên cứu bao gồm các thông số trước, trong và sau mổ. Xử lý số liệu bằng phần mềm thống kê $\mathrm{y}$ học SPSS 20.0

\section{KẾT QUẢ}

Bảng 1: Phân bố về giới

\begin{tabular}{lll}
\hline Giới & $\mathbf{n}$ & \% \\
\hline Nam & 168 & 85,3 \\
Nữ & 29 & 14,7 \\
Tổng & 197 & 100 \\
\hline
\end{tabular}

Nhân xét: Tỷ lệ nam chiếm nhiều hơn nữ giới. So với tác giả Ba Lan nam 79,1\%, nữ 29,1\%[7]. Với Lâm Văn Nút nam 80\%, nữ 20\%[5].

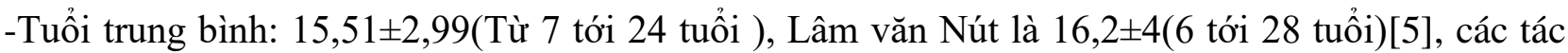

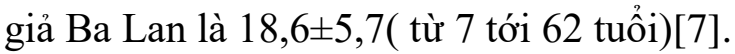

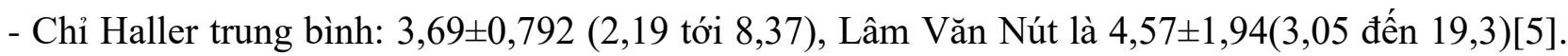
Của tác giả Ba Lan là $3,7 \pm 1,4(2,6$ đến 17,3)[7].

Bảng 2: Phân loại lõm ngục theo Park

\begin{tabular}{lll}
\hline Thể lõm & $\mathbf{n}$ & $\mathbf{\%}$ \\
\hline $\mathbf{1 A}$ & 131 & 66,5 \\
$\mathbf{1 B}$ & 36 & 18,3 \\
$\mathbf{2 A}$ & 20 & 10,2 \\
$\mathbf{2 B}$ & 10 & 5,1 \\
$\mathbf{2 C}$ & 0 & 0 \\
$\mathbf{3}$ & 0 & 0 \\
Tổng & 197 & 100 \\
\hline
\end{tabular}

Nhân xét: Bệnh nhân lõm ngực đồng tâm khu trú chiếm tỷ lệ cao. 
Bảng 3: Hình thái của lõm trên lâm sàng

\begin{tabular}{lll}
\hline Tính chất đối xứng của hố lõm & $\mathbf{N = 1 9 7}$ & \% \\
\hline Đối xứng & 166 & 84,3 \\
Không đối xứng & 31 & 15,7 \\
Tổng & 197 & 100 \\
\hline
\end{tabular}

Nhân xét: Chủ yếu là lõm ngực đối xứng, so với các tác giả Ba Lan đối xứng là 66,1\%, không đối xứng là $33,9 \%$ [7].

Bảng 4: Hình thái trên phim chụp cắt lớp điện toán

\begin{tabular}{lll}
\hline Hình thái & n & $\%$ \\
\hline Xương ức cân đối & 113 & 57,4 \\
\hline Xương ức ghiêng phải & 67 & 34 \\
Xương ức nghiêng trái & 17 & 8,6 \\
Tổng & 197 & 100 \\
\hline
\end{tabular}

Nhân xét: Xương ức cân đối chiếm tỷ lệ cao 57,4\%. Xương ức xoắn vặn nghiêng phải là chủ yếu.

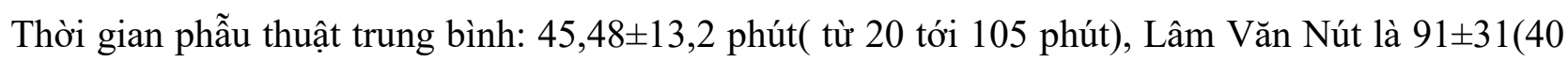

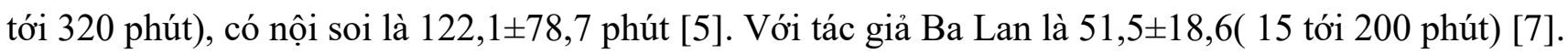

Bảng 5: Phân bố số thanh đơ được đặt cho bệnh nhân

\begin{tabular}{lll}
\hline Số thanh đõ & $\mathbf{n}$ & $\%$ \\
\hline $\mathbf{1}$ thanh & 194 & 98,5 \\
$\mathbf{2}$ thanh & 3 & 1,5 \\
Tổng & 197 & 100 \\
\hline
\end{tabular}

Nhận xét: Bệnh nhân chỉ cần đặt 01 thanh chiếm tỷ lệ cao

- 100\% bệnh nhân không có biến chứng trong mổ như: chảy máu trong và sau mổ, tổn thương phổi, cơ hoành, tổn thương gan.

- 02 bệnh nhân tồn dư khí chiếm $1 \%$.

- 01 bệnh nhân có biến chứng tràn khí khoang màng phổi, phải đặt dẫn lưu khoang màng phổi 2 bên chiếm $0,5 \%$.

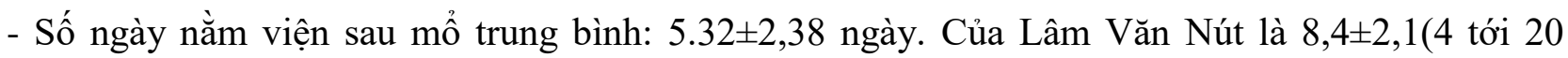
ngày) [5]. Tác giả Ba Lan là 6,3 \pm 2 (3 tới 20 ngày) [7] 


\section{BÀN LUẬN}

Theo phương pháp phẫu thuật Nuss kinh điển được Donal Nuss công bố 1998 là phẫu thuật ít xâm lấn luồn thanh dẫn từ phải qua trái không có nội soi hỗ trợ. Phương pháp này sau đó đã được phát triển ra nhiều nơi trên thế giới. Theo tiến trình phát triển của phương pháp này đã có một và thay đổi như thêm nội soi hỗ trợ, cách cố định thanh đỡ... nhưng bên dùng nội soi tiếp cận vào lồng ngực vẫn chủ yếu là từ phải qua trái. Mặc dù tỷ lệ thành công là rất cao $(>90 \%)[8]$ nhưng các nghiên cứu cũng chỉ ra vẫn còn những biến chứng nghiêm trọng liên quan tới phẫu thuật cần phải có biện pháp giải quyết như: Tổn thương tim, phổi, cơ hoành, chọc trocar vào gan phải...[3]. Xuất phát từ lập luận trên chúng tôi tiến hành phẫu thuật Nuss có nội soi hỗ trợ vào lồng ngực từ bên trái bằng một đường rạch da nhỏ phía dưới khoang liên sườn đặt thanh dẫn khoảng 02 khoang liên sườn (Phẫu thuật Nuss cải tiến: Sử dụng nội soi hỗ trợ và tiếp cận vào khoang lồng ngực từ bên trái). Chúng tôi chọn tiếp cận vào khoang lồng ngực do: Thứ nhất là giải phẫu của tim có đáy nằm chếch lên trên (diện tiếp xúc của tim chủ yếu nằm ở bên trái lồng ngực nên khi tiếp cận từ bên trái sẽ kiểm soát tốt hơn) và bên phải chủ yếu tạo nên bởi nhĩ phải thành mỏng; Thư hai là đỉnh tim nằm chếch xuống dưới sang trái, mặt trước là thất trái cơ dày tạo với thành ngực trước một góc nhọn sẽ dễ dàng tạo đường hầm dưới xương ức và trước màng ngoài tim mà không có biến chứng. Hơn nữa, chúng tôi sử dụng banh hình tim tạo đường hầm trước khi dùng thanh hướng dẫn luồn qua đường hầm này nên rất an toàn và rõ ràng trong phẫu thuật. Thú ba là khi bơm khí $\mathrm{CO}_{2}$ (áp lực $5 \mathrm{mmHg}$ ) vào khoang màng phổi thì nhu mô phổi xẹp tốt hơn tạo dễ dàng cho việc luồn chỉ thép cố định thanh đỡ vào xương sườn. Do vậy khi vào lồng ngực từ bên trái có nội soi hỗ trợ sẽ giúp kiểm soát tim tốt hơn và không liên quan tới gan trong quá trình phẫu thuật [9]. Sử dụng hệ thống nội soi giúp quan sát tốt điểm vào và ra của thanh dẫn nên kiểm soát tốt vẫn đề chảy máu, kẹp vào phổi và đặc biệt là vấn đề tạo đường hầm qua mặt sau xương ức. Mặt khác, qua camera nội soi giúp cho vấn đề "đuổi khí" trong lồng ngực trước khi kết thúc phẫu thuật bằng cách quan sát trực tiếp sự giãn nở của nhu mô phổi và hỗ trợ luồn chỉ thép cố định thanh đỡ vào xương sườn. Cố định thanh đỡ bằng chỉ thép với xương sườn giúp tiết kiệm chi phí và vững chắc.

Với phương pháp như trên kết quả đạt được của chúng tôi là như sau: Độ tuổi trung bình $15,51 \pm 2,99$ tuổi.

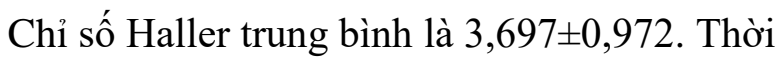
gian phẫu thuật trung bình của chúng tôi 45,48ะ13,2 phút. Có 02 bệnh nhân được ghi nhân có tồn dư khí $\mathrm{CO} 2$ sau mổ liên quan tới “đuổi khî” khoang màng phổi sau mổ, chỉ cần chọc hút bằng kim lấy thuốc chiếm $01 \%$. Có 01 bệnh nhân gặp biến chứng tràn khí sau mổ cần đặt dẫn lưu khoang màng phổi hai bên nhưng không có kết quả do vỡ kén khí thùy trên phổi phải được chỉ định mổ nội soi cắt kén khí, bệnh nhân ổn định ra viện sau 35 ngày điều trị. Không có bệnh nhân nào bị chảy máu trong và sau mổ, không có bệnh nhân nào bị tổn thương phổi, cơ hoành hay gan. So sánh với nghiên cứu khác như Lâm văn Nút 2014 trên 229 bệnh nhân ,thời gian phẫu thuật trung bình 91(phút), phẫu thuật có nội soi hỗ trợ là 08 ca thời gian trung bình là $122,1 \pm 78,7$ phút, lượng máu mất trong mổ có 1 trường hợp $1000 \mathrm{ml}$, số ngày nằm viện trung bình 8,4 (ngày), dẫn lưu khoang màng phổi trong lúc phẫu thuật là 
$6,6 \%[5]$. Với một nghiên cứu của nhóm tác giả tại $\mathrm{Ba}$ Lan công bố trên 1006 bệnh nhân năm 2018 kéo dài từ 2002-2016 phẫu thuật theo phương pháp Nuss có nội soi hỗ trợ vào lồng ngực từ trái qua phải như sau: Độ tuổi trung bình 18,6 tuổi (07 đến 62 tuổi). Thời gian phẫu thuật trung bình $51,5 \pm 18,6$ phút (từ 18 tới 200 phút), biến chứng sau phẫu thuật phần lớn là không nghiêm trọng, thường gặp nhất là tràn khí màng phổi có 244 bệnh nhân được chẩn đoán, chỉ có 74 bệnh nhân trong số đó phải can thiệp đặt 1 dẫn lưu là ổn định, số bệnh nhân còn lại không cần can thiệp gì, có 13 bệnh nhân chảy máu sau mổ 07 bệnh nhân trong số đó cần dẫn lưu, 1 bệnh nhân phải truyền 01 dơn vị máu. Không có bệnh nhân nào chảy máu trong mổ phải đặt dẫn lưu[7].

\section{KẾT LUẬN}

Phẫu thuật Nuss cải tiến có nội soi hỗ trợ với đường tiếp cận vào lồng ngực từ bên trái điều trị bệnh lõm ngực bẩm sinh là phương pháp hiệu quả, an toàn và ít biến chứng.

\section{TÀI LIỆU THAM KHẢO}

1. D. Nuss, R. E. Kelly, Jr., D. P. Croitoru và cộng sự (1998). A 10-year review of a minimally invasive technique for the correction of pectus excavatum. J Pediatr Surg, 33 (4), 545-552.

2. Anthony J. Bufo và M. M. Stone (2001). Add chest thoracoscopy to Nuss Pectus Repairatum Repair. Pediatric Endoscopic \&
Creative Technology, 5 (2),

3. C. Castellani, J. Schalamon, A. K. Saxena và cộng sự (2008). Early complications of the Nuss procedure for pectus excavatum: a prospective study. Pediatr Surg Int, 24 (6), 659-666.

4. S. Choi và H. J. Park (2017). Complications after pectus excavatum repair using pectus bars in adolescents and adults: risk comparisons between age and technique groups. Interact Cardiovasc Thorac Surg, 25 (4), 606-612.

5. L. V. Nút (2008). Kỹ thuật can thiệp tối thiểu trong phẫu thuật bệnh lõm ngực. Tạp chi $y$ học Việt Nam, Tổng hội y học Việt Nam, (352), 522-528.

6. Nguyễn Hữu Ước, Ngô Gia Khánh và N. V. Trường (2012). So sánh điều trị lõm ngực bẩm sinh giữa mổ mở kinh điển và phẫu thuật Nuss tại bệnh việnViệt Đức. Phẫu thuật tim mạnh và lồng ngục Việt Nam, (2), 25-28.

7. K. Pawlak, L. Gasiorowski, P. Gabryel và cộng sự (2018). Video-assisted-thoracoscopic surgery in left-to-right Nuss procedure for pectus excavatum for prevention of serious complications - technical aspects based on 1006 patients. Wideochir Inne Tech Maloinwazyjne, 13 (1), 95-101.

8. D. Nuss, R. J. Obermeyer và R. E. Kelly (2016). Nuss bar procedure: past, present and future. Ann Cardiothorac Surg, 5 (5), 422-433. 